\title{
Research on Psychological Capital of College Graduates: The Mediating Effect of Coping Styles
}

\author{
Qiangwei Yan ${ }^{1, a}$, Lei Zhang ${ }^{2}$, * \\ ${ }^{1,2}$ Wuhan Textile University, Wuhan, 430200,China \\ a email, b* lei.zhang@wtu.edu.cn
}

Key words: College Graduates, PsyCap, Coping Styles

\begin{abstract}
A total of 832 college graduates in Wuhan City were selected as participants to analyze their psychological capital (PsyCap) and coping styles, using the method of cluster sampling. Data were collected via the PsyCap Questionnaire (PCQ) and the Simplified Coping Style Questionnaire (SCSQ).This paper aims to explore the influences of coping styles on interpersonal relationships and academic performances when PsyCap acts as the mediating variable, and to explore the influences of family relations on PsyCap when coping styles acts as the mediating variable.
\end{abstract}

\section{Introduction}

Psychological capita (PsyCap) was proposed by Luthans and his colleagues in 2004, drawn from positive psychology and organizational behavioristics. PsyCap refers to a positive state of mind exhibited during the growth and development of an individual, which mainly includes self-efficacy, hope, resilience and optimism (Luthans et al., 2007). The positive psychological state, which was showed in PsyCap, affects the individual's perceptions, attitudes and behaviors. Coping is coping styles, which defined as the set of cognitive and behavioural strategies used by an individual to manage the internal and external demands of stressful situations. It is an important intermediary factor in the process of psychological stress. Coping styles of individuals, which plays an important role in the individuals' physical and mental health regulates the relationship between stressors and stress results. It is strategies or methods to deal with stressful situations and to maintain psychological balance.

With the rapid development of economy and the widespread of higher education, problems of graduates' employment have become a hot issue of society. College students during their employment are faced with three kinds of contradictions and conflicts: firstly, the change of roles, which means a student at school becomes an employee in society; secondly, the change of pocketbooks, which means most college students must make money by themselves instead of given money by their parents after graduation; thirdly, the contradictions and conflicts between high expectations to the future career and the reality of the actual remuneration.

In this paper, college graduates refer to the senior graduates (undergraduate) or the junior graduates (college) faced with job hunting or further study, and hereinafter referred to as "college graduates". When college graduates are confronted with these contradictions and conflicts, i.e. stressors, the coping styles will affect their physical and mental health, thereby affecting the PsyCap. This study mainly investigates on the college students' PsyCap and coping styles, probing into influences of PsyCap on college students' coping styles, interpersonal relationships and academic performances; at the same time, we explore the influences of coping styles on interpersonal relationships and academic performances when PsyCap acts as the mediating variable, and explore the influences of family relations on PsyCap when coping styles acts as the mediating variable. Finally, we expect to provide reference for mental health and occupational guidance of college students.

Coping styles of college graduates significantly affect their interpersonal relationships and academic performances, while the PsyCap plays a mediating role between coping styles and interpersonal relationships, coping styles and academic performances, and specific items are shown in Figure 1: 


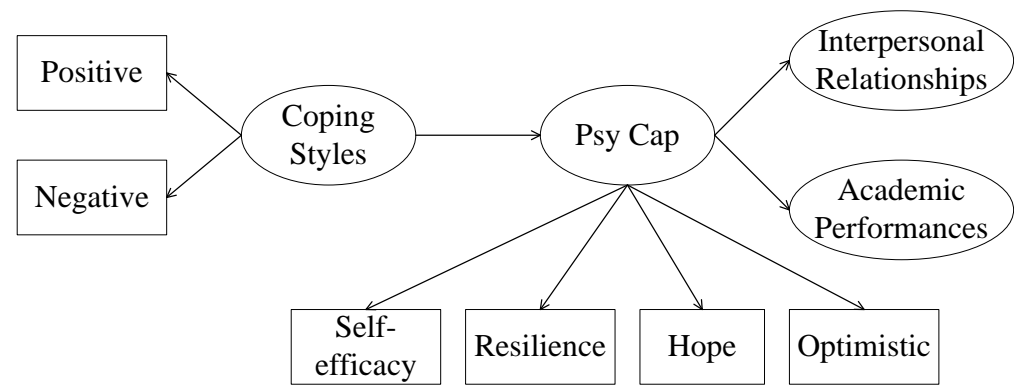

Figure 1 The model of PsyCap as the mediator

Family relations of college graduates significantly affect their coping styles and PsyCap,while coping styles play a mediating role between family relations and PsyCap,and specific items are shown in Figure 2:

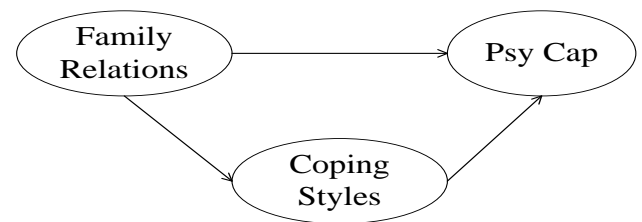

Figure 2 The model of coping styles as the mediator

\section{Subjects, Methods and Samples}

The subjects of research. A total of 840 college students (effective responses are 832) were selected with the method of cluster sampling in Wuhan City to conduct the questionnaires (Guilin Zheng et al., 2015).The questionnaires were completed and recycled on site.

The tools of research. The questionnaire consists of three parts:the first part is the basic situation of college graduates (including the demographic status,the family situation and professional subjects etc.); the second part is the Simplified Coping Style Questionnaire; the third part is PsyCap (positive psychological qualities) Questionnaire, i.e. PCQ.

The Simplified Coping Style Questionnaire (SCSQ) was used to measure coping styles of college graduates (Xie Yaling,1998), which included two dimensions: the positive coping and negative coping, and the grades " $0,1,2,3$ " represented separately "never, occasionally, sometimes, frequently".

The PsyCap of college graduates was measured with the Psychological Capital Questionnaire (PCQ) which was developed by Luthans and his colleagues (Li Li et al., 2012). The PCQ included four dimensions: self-efficacy, hope, resilience and optimism. Those items were scored on a seven-point scale ranging from 1 (strongly disagree) to 6 (strongly agree). Higher values indicated higher levels of PsyCap.

Methods of investigation of PsyCap. This research test on the collectivity and analyze statistical data using the SPSS13.0.

The samples. In this study,the basic characteristic variables were grade, gender, student cadre, single-child, origin, economic status, single-parent family, with a view to a more comprehensive, multi-angle investigation of college graduates' positive psychological qualities and coping styles. Academic performances, family relations and interpersonal relationships were measured by the way of self-assessment. The academic performance is "inferior, middle, superior", and the family relation is "alienated, ordinary, intimate", while the interpersonal relationship as "poor, general, good”, and the score is" 1, 2, 3”, respectively. Specific conditions are shown in Table 1: 
Table 1: $\quad$ The conditions of samples $(\mathrm{N}=832)$

\begin{tabular}{cccccccc}
\hline Variable & $\begin{array}{c}\text { Characteri } \\
\text { stic }\end{array}$ & Number & Percent\% & Variable & $\begin{array}{c}\text { Characteri } \\
\text { stic }\end{array}$ & Number & Percent\% \\
\hline \multirow{5}{*}{ Grade } & Grade 1 & 258 & 31.0 & & Rich & 7 & 0.9 \\
& Grade 2 & 147 & 17.7 & Economic & Normal & 606 & 72.8 \\
& Grade 3 & 18 & 2.2 & status & Poor & 219 & 26.3 \\
& Grade 4 & 409 & 49.1 & & City & 208 & 25.0 \\
Gender & Male & 319 & 38.4 & Origin & Country & 624 & 75.0 \\
& Female & 513 & 61.6 & Single & Yes & 65 & 8.8 \\
Single & Yes & 298 & 35.8 & parent & No & 767 & 92.2 \\
child & No & 534 & 64.2 & family & & & \\
& & & & & & & \\
& Inferior & 43 & 5.2 & Student & Yes & 276 & 33.2 \\
& Middle & 627 & 75.4 & cadre & No & 556 & 66.8 \\
& Superior & 162 & 19.4 & & & & \\
& & & & & & & \\
Family & Intimate & 706 & 84.9 & Interperso & Good & 340 & 40.9 \\
relation & Ordinary & 122 & 14.7 & relationshi & Normal & 481 & 57.8 \\
& Alienated & 4 & 0.4 & Poor & 11 & 1.3 \\
\hline
\end{tabular}

\section{Results}

The analysis on the state of college graduates' PsyCap. Through analyzing the mean value of the positive PsyCap of college graduates and taking the variance homogeneity test and the independent sample T-test in each demographic dimension (in Table 2), we could see that the PsyCap of college graduates was in good condition as a whole,and the score was between 4.7 and 5.2, where the factor of "hope" scored the highest, followed by "optimistic" and "resilience", and the lowest score was "self-efficacy”.

Table 2 The state of college graduates’ PsyCap (Mean)

\begin{tabular}{cccccc}
\hline & Self-efficacy & Hope & Resilience & Optimistic & PsyCap \\
\hline Generality & $4.696 \pm 0.815$ & $5.245 \pm 1.023$ & $4.806 \pm 1.023$ & $5.159 \pm 0.891$ & $4.979 \pm 0.738$ \\
\hline
\end{tabular}

The analysis on the state of college graduates' coping styles. Through analyzing the mean value of coping styles of college graduates and taking the variance homogeneity test and the independent sample T-test in each demographic dimension (in Table 3), we could see that college graduates commonly adopted the positive coping (the positive coping scored higher than the negative coping).

Table 3 The state of college graduates’ coping styles (Mean)

\begin{tabular}{ccc} 
& Positive coping & Negative coping \\
\hline Generality & $2.051 \pm 0.351$ & $1.033 \pm 0.472$ \\
\hline
\end{tabular}

The correlation analysis on the positive PsyCap, coping styles, interpersonal relationships and academic performances of college graduates. According to the analysis of Pearson's product-moment correlation on graduates' positive PsyCap, coping styles, interpersonal relationships and academic performances, the results showed that: each factor's score and the total score of PsyCap had a significant positive relation with the positive coping $(\mathrm{P}<0.01)$,and the factor of "resilience" $(\mathrm{P}<0.01)$ and the total score of PsyCap $(\mathrm{P}<0.05)$ had a negative correlation with the negative coping; each factor's score and the total score of PsyCap had a significant positive relation with interpersonal relationships $(\mathrm{P}<0.01)$;the factors of "self-efficacy" and "hope" had a significant positive correlation with academic performances $(\mathrm{P}<0.01)$, while the correlation between the total score of PsyCap and academic performances did not pass the test of significance; the factors of 
"hope" ( $\mathrm{P}<0.05)$,"resilience" $(\mathrm{P}<0.01)$ and the total score $(\mathrm{P}<0.01)$ had a significant positive correlation with family relations; the positive coping had a significant positive correlation with interpersonal relationships $(\mathrm{P}<0.01)$, while the negative coping had a significant negative correlation with interpersonal relationships $(\mathrm{P}<0.01)$; the correlation between the positive coping, the negative coping and academic performances did not pass the test of significance; the positive coping had a significant positive relation with family relations $(\mathrm{P}<0.05)$, while the correction between negative coping and family relations did not pass the test of significance.

Table 4 Correlation analysis of each dimension (Pearson)

\begin{tabular}{clllllll}
\hline & Self-efficacy & Hope & Resilience & Optimist & PsyCap & $\begin{array}{c}\text { Positive } \\
\text { coping }\end{array}$ & $\begin{array}{c}\text { Negative } \\
\text { coping }\end{array}$ \\
\hline $\begin{array}{c}\text { Positive } \\
\text { coping }\end{array}$ & $0.368^{*}$ & $0.390^{* *}$ & $0.185^{* *}$ & $0.489^{* *}$ & $0.458^{* *}$ & 1 & 0.105 \\
$\begin{array}{c}\text { Negative } \\
\text { coping }\end{array}$ & -0.102 & $-0.150^{*}$ & $-0.203^{* *}$ & -0.034 & $-0.160^{*}$ & 0.105 & 1 \\
$\begin{array}{c}\text { Interpersonal } \\
\text { relationship } \\
\text { Academic }\end{array}$ & $0.367^{* *}$ & $0.310^{* *}$ & $0.252^{* *}$ & $0.276^{* *}$ & $0.389^{* *}$ & $0.259^{* *}$ & $-0.148^{* *}$ \\
$\begin{array}{c}\text { performance } \\
\text { Family } \\
\text { relation }\end{array}$ & $0.146^{* *}$ & $0.214^{*}$ & -0.060 & 0.065 & 0.116 & 0.127 & 0.017 \\
\hline
\end{tabular}

** Indicates significant correlation at the level of $0.01, *$ indicates significant correlation at the level of 0.05

The mediating role of PsyCap and coping styles. According to the method of examining the mediating role, which was put forward by Baron and others: first, the independent variable had significant explanatory power on the dependent variable; second,the independent variable had significant explanatory power on the mediating variable; third, when the independent variable and the mediating variable simultaneously acted on the dependent variable, if the independent variable affected significantly, then the mediating variable was a partial mediator; if the coefficient of the independent variable was not significant,then the mediating variable was a full mediator (Baron et al.,1986).As can be seen from the above analysis,coping styles and learning achievements of college graduates wasn't significantly related,and the negative coping and family relations also wasn't significantly related.Therefore,using the hierarchical regression to test the mediating role of PsyCap between coping styles and interpersonal relationships, respectively,and the mediating role of the positive coping between family relations and the PsyCap,and the specific results are as follows:

The mediating effect of the PsyCap between the positive coping and interpersonal relationships. As can be seen from Table 5,in model 1,the positive coping had a significant regression coefficient on interpersonal relationships $(\beta=0.259, \mathrm{P}<0.001)$, and in model 2, it also had a significant regression coefficient on PsyCap $(\beta=0.440, \mathrm{P}<0.001)$; in model 3, when positive coping and PsyCap simultaneously acted on,the prediction effect on interpersonal relations was significantly improved (14.5\%), and the regression coefficient of the positive coping did not pass the test of significance $(\beta=0.116, P>0.05)$, while the regression coefficient of PsyCap was significant $(\beta=0.326$, $\mathrm{P}<0.001$ ), which showed that PsyCap played a fully mediating role in the negative coping and interpersonal relationships.

Table 5 the mediating role of PsyCap in the positive coping and interpersonal relationships

\begin{tabular}{llllllll}
\hline Regression model & $\mathrm{R}^{2}$ & $\mathrm{~F}$ & $\mathrm{P}$ & $\mathrm{B}$ & Beta & $\mathrm{t}$ & $\mathrm{P}$ \\
\hline $\begin{array}{l}\text { Model 1: the positive } \\
\begin{array}{l}\text { coping-interpersonal } \\
\text { relationship }\end{array}\end{array} 0.063$ & 16.568 & 0.000 & 0.381 & 0.259 & 4.070 & 0.000 \\
$\begin{array}{l}\text { Model 2: the positive } \\
\text { coping- PsyCap }\end{array}$ & 0.190 & 55.100 & 0.000 & 0.917 & 0.440 & 7.423 & 0.000 \\
\hline
\end{tabular}




\begin{tabular}{llllllll}
\hline $\begin{array}{l}\text { Model 3: the positive } \\
\text { coping and }\end{array} \quad 0.145$ & 20.634 & 0.000 & & & & \\
$\begin{array}{l}\text { PsyCap_interpersonal } \\
\text { relationship }\end{array}$ & & & & & & \\
$\begin{array}{l}\text { The positive coping } \\
\text { PsyCap }\end{array}$ & & 0.171 & 0.116 & 1.714 & 0.088 \\
\hline
\end{tabular}

The mediating effect of the PsyCap between the negative coping and interpersonal relationships. As can be seen from Table 6,in model 1,the negative coping had a significant regression coefficient on interpersonal relationships $(\beta=-0.148, \mathrm{P}<0.05)$, and in model 2 , it also had a significant regression coefficient on $\operatorname{PsyCap}(\beta=-0.156, \mathrm{P}<0.05)$;in model 3, when negative coping and PsyCap simultaneously acted on, the prediction effect on interpersonal relations was significantly improved(14.3\%),the regression coefficient of the negative coping did not pass the test of significance $(\beta=-0.091, \mathrm{P}>0.05)$, while the regression coefficients of PsyCap was significant ( $\beta=0.362, \mathrm{P}<0.001$ ), which showed that PsyCap played a fully mediating role in the negative coping style and interpersonal relationships.

Table 6 the mediating role of PsyCap in the negative coping and interpersonal relationships

\begin{tabular}{|c|c|c|c|c|c|c|c|}
\hline Regression model & $\mathrm{R}^{2}$ & $\mathrm{~F}$ & $\mathrm{P}$ & B & Beta & $\mathrm{t}$ & $\mathrm{P}$ \\
\hline $\begin{array}{l}\text { Model 1: the negative } \\
\text { coping-interpersonal } \\
\text { relationship }\end{array}$ & 0.018 & 5.140 & 0.024 & -0.162 & -0.148 & -2.267 & 0.024 \\
\hline $\begin{array}{l}\text { Model 2: the negative } \\
\text { coping- PsyCap }\end{array}$ & 0.020 & 5.704 & 0.018 & -0.241 & -0.156 & -2.388 & 0.018 \\
\hline $\begin{array}{l}\text { Model 3: the negative } \\
\text { coping } \\
\text { PsyCap_interpersonal } \\
\text { relationship }\end{array}$ & 0.143 & 20.203 & 0.000 & & & & \\
\hline The negative coping & & & & -0.100 & -0.091 & -1.483 & 0.139 \\
\hline PsyCap & & & & 0.255 & 0.362 & 5.875 & 0.000 \\
\hline
\end{tabular}

The mediating effect of the positive coping between family relations and the PsyCap. As can be seen from Table 7,in model 1,family relations had a significant regression coefficient on the PsyCap ( $\beta=0.182, \mathrm{P}<0.01$ ), and in model 2 , it also had a significant regression coefficient on the positive coping $(\beta=0.154, \mathrm{P}<0.05)$;in model 3 , when family relations and the positive coping simultaneously acted on,the prediction effect on the PsyCap was significantly improved (20\%),and the regression coefficient of family relations did not pass the test of significance $(\beta=0.117, \mathrm{P}>0.05)$, while the regression coefficient of the positive coping was significant $(\beta=0.422, \mathrm{P}<0.001)$, which showed that the positive coping played a fully mediating role in family relations and the PsyCap.

Table 7 the mediating role of the positive coping $t$ between family relations and PsyCap

\begin{tabular}{|c|c|c|c|c|c|c|c|}
\hline Regression model & $\mathrm{R}^{2}$ & $\mathrm{~F}$ & $\mathrm{P}$ & B & Beta & $\mathrm{t}$ & $\mathrm{P}$ \\
\hline $\begin{array}{l}\text { Model 1:the family } \\
\text { relation--PsyCap }\end{array}$ & 0.029 & 7.837 & 0.006 & 0.355 & 0.182 & 2.799 & 0.006 \\
\hline $\begin{array}{l}\text { Model 2:the family } \\
\text { relation-- the positive } \\
\text { coping }\end{array}$ & 0.019 & 5.588 & 0.019 & 0.144 & 0.154 & 2.364 & 0.019 \\
\hline $\begin{array}{l}\text { Model 3:the family } \\
\text { relation and positive } \\
\text { coping-interpersonal } \\
\text { relationship }\end{array}$ & 0.200 & 29.804 & 0.000 & & & & \\
\hline Family relation & & & & 0.228 & 0.117 & 1.957 & 0.052 \\
\hline The positive coping & & & & 0.880 & 0.422 & 7.078 & 0.000 \\
\hline
\end{tabular}




\section{Research on the Verification of Hypothesis}

As can be seen from the above statistical analysis, coping styles of college graduates have a significant impact on interpersonal relationships and academic performances, while the PsyCap plays a mediating role between coping styles and interpersonal relationships, coping styles and academic performances; family relations of college graduates have a significant impact on their coping styles and PsyCap, and coping styles play a mediating role between family relations and PsyCap.The hypotheses of this study have been verified

\section{Conclusions and Recommendations}

The PsyCap of college graduates is in good condition as a whole. Through empirical analysis, we can see that the PsyCap of college graduates is in good condition as a whole, and they commonly adopt the positive coping. The overall situation of PsyCap has significant differences in family relations and interpersonal relationships, and the positive coping has significant differences in family relations. The contemporary 90 s college graduates could adopt the positive coping to resolve difficulties and setbacks encountered in practical life when faced with the pressures of role change and job hunting, and they generally have a positive PsyCap. Universities widespread pay attention to students' mental health, and popularize the mental health education according to the different characteristics of students, which is started from the freshmen. The model change from "solve-based of psychological problems" to "cultivate-based of positive attitudes", and also means and strategies are more diverse.

The relationship between coping styles,the PsyCap and interpersonal relationships of college graduates. The positive coping of college graduates has a significant positive impact on the PsyCap, while the negative coping has a significant negative impact on the PsyCap;the PsyCap has a significant positive impact on interpersonal relationships; the positive coping has a significant positive impact on interpersonal relationships, while the negative coping has a significant negative impact on interpersonal relationships;when coping styles and the PsyCap simultaneously act on,the prediction effect on interpersonal relations is significantly improved, and the PsyCap fully mediated between coping styles and interpersonal relationships.It is particularly important for college graduates to handle interpersonal relationships at work during the period of job hunting and internship.So possessing more positive psychological capitals apparently helps college graduates quickly to adapt to life in the workplace,to complete the transformation of the role,to adopt positive coping strategies when faced with new difficulties and challenges.

The relationship between family relations,coping styles and the PsyCap of college graduates. Family relations of graduates has a significant positive impact on the PsyCap; family relations has a significant prediction on the positive coping; when family relations and the positive coping simultaneously act on,the prediction effect on the PsyCap is significantly improved, and the positive coping fully mediates between family relations and the PsyCap. Family relations belong to the environmental resources (the family support in the social supports) in the individual coping resources,thus which kind of coping strategies adopted by the individual will be affected by the environmental resources. College graduates who have a more intimate family relation are more inclined to adopt the positive coping. Vitaliano found that the good coping style helps to maintain psychological balance, to protect mental health(Vitaliano et al.,1987).Mental health education of universities or colleges should tend to intervene and train their coping styles,to focus on the development and prevention of the healthy group,to pay attention to enrich their knowledge of coping strategies, to train their coping capacity (Ostrovsky et al.,2011).So college graduates need to posses both professional knowledge and the positive PsyCap at the same time,in order to have a good start in the future career.

\section{Acknowledgements}

This paper is the result of humanities and social sciences research project "Research on the Mode 
of College Students' Education and Development under Perspective of Positive Psychological Capital" (Project Number: 1516B10) of Education Department of Hubei Province in 2015.

Fund Project: Humanities and social scientific research special task of project in the year 2015 Hubei Province Department of education, the 2015-2016 year Hubei college students work study will project "from the perspective of positive psychological capital development of college students education mode of", project number 1516B10.

\section{References}

[1] Luthans F, Youssef C M, Avolio B J. PsyCap Developing the Human Competitive Edge[M]. Oxford, UK: Oxford University Press, 2007: 1-2.

[2] Li Li, Liao Xiaoming. Positive PsyCap: Measuring and Their Relationships with Coping Styles[J]. Higher Studies of Heilongjiang Province, 2012 (9): 37-40.

[3] Baron, RM, Kenny, DA. The Moderator-Mediator Variable Distinction in Social Psychological Research: Conceptual, Strategic, and Statistical Considerations [J]. Journal of Personality and Social Psychology, 1986, 51 (6): 1173-1182.

[4] Wang Jianzhong, Song Junqing. Functional Mechanism of PsyCap on Career Development of University Students [J]. Journal of Liaoning University (Philosophy and Social Sciences), 2011, 39 (2): 116-121.

[5] Vitaliano P P, Maiuro R D, Russo J, et al. Raw versus relative scores in the assessment of coping strategies [J] Journal of Behavioral Medicine 1987, 10 (1):1-18. 